\title{
Microbial community changes in contaminated soils in response to phenanthrene amendment
}

\author{
S. Y. Zhang; Q. F. Wang; *S. G. Xie \\ College of Environmental Sciences and Engineering, Peking University, Beijing 100871, China
}

Received 12 November 2010; $\quad$ revised 21 December 2010; $\quad$ accepted 23 February 2011

\begin{abstract}
Leachate and reclaimed wastewater have become the important sources of polycyclic aromatic hydrocarbons in soils. However, the information on bioremediation of leachate and reclaimed wastewater-contaminated soils is still lacking. Identification of changes in microbial structure or of enriched genera related to biodegradation could aid identification of particular organisms or consortia capable of degrading polycyclic aromatic hydrocarbons in these contaminated soils. In this study, terminal restriction fragment length polymorphism, coupled with 16S Ribosomal ribonucleic acid clone library analysis, was applied to investigate the composition of bacterial community in leachate-contaminated soil or grassland soil irrigated reclaimed wastewater and the response to phenanthrene amendment. Results showed that phenanthrene amendment had significant but different impacts on microbial community structure, dependent on soil source. Several greatly enriched terminal restriction fragments with phenanthrene biodegradation were identified. Moreover, genus rhizobacteria, possibly linked to phenanthrene biodegradation, was firstly reported in this study. This work might provide some new insights into bioremediation of polycyclic aromatic hydrocarbons-contaminated soils.
\end{abstract}

Keywords: Biodegradation; Landfill leachate; Polycyclic aromatic hydrocarbons; Reclaimed wastewater; Terminal polymorphism

\section{INTRODUCTION}

Polycyclic aromatic hydrocarbons (PAHs) are a group of chemical compounds consisting of carbon and hydrogen, arranged in the form of two or more aromatic rings. The ubiquitous existence of PAHs in the environment has caused great environmental concerns because of their persistence, toxicity, mutagenicity and carcinogenicity (Haritash and Kaushik, 2009; Arulazhagan et al., 2010). PAHs are released into the environment from the incomplete combustion of fossil fuels and organic matter, the accidental spilling of processed hydrocarbons and oils, runoff from asphalt pavements, coal liquefaction and gasification and natural geological processes (Yuan et al., 2000). However, other important sources of PAH contamination have also aroused the great attention of environmental researchers. Several researches have shown the high content of PAHs in soils where wastewater is reused for land application (Tao et al., 2004; Chen et al., 2005; He et al., 2010). Moreover, landfill leachate may cause the significant PAH

\footnotetext{
× *Corresponding Author Email: xiesg@pku.edu.cn
} Tel.: +86106275 1923; Fax: +86106275 1923 contamination of soil in the vicinity of the site where municipal solid waste is dumped in a more or less uncontrolled manner (Han et al., 2009). Bioremediation, the use of microorganisms to clean up contaminated soil, is an environmentally safe solution for PAH removal (Yousefi Kebria et al., 2009; Abdulsalam et al., 2011). However, the information on bioremediation of these two kinds of PAH-contaminated soils is still lacking. PAHs have a significant effect on bacterial community structure in soil (He, 2008; Muckian et al., 2009). Identification of changes in microbial structure or of enriched genera related to PAH biodegradation could aid in identification of particular organisms or consortia capable of degrading PAHs in contaminated soil. Therefore, the knowledge about the structure of microbial community in PAH contaminated site is important if bioremediation is to be applied as an effective technology (MacNaughton et al., 1999; Cunliffe and Kertesz, 2006; Grant et al., 2007). Unfortunately, the few works, in relationship with the impacts of the reclaimed wastewater application on soil bacterial community, have usually neglected the links 
of PAHs (Zhang, 2008). Moreover, there is still no information about the composition of microbial community in leachate-contaminated soil. The PAH content in contaminated soils usually increased with time, due to subsequent longer exposure to reclaimed wastewater (He et al., 2010) or landfill leachate (Han et al., 2009), implying contaminated site continuously received PAH amendment. Unfortunately, very few investigations have been undertaken to assess the impact of PAH amendment on soil microbial community in PAH-contaminated site (Muckian et al., 2009). As a consequence, the microbial community in the reclaimed wastewater- or leachate-contaminated soils and its change associated with longer exposure to PAHs remains largely unclear.

Given that microbial communities are metabolically both diverse and highly tuned to their specific habitats, monitoring microbial population dynamics in an environmental system can be a sensitive method to track changes (Mills et al., 2003; Arulazhagan et al., 2010).Molecular approaches such as terminal restriction fragment length polymorphism (TRFLP), denaturing gradient gel electrophoresis (DGGE), thermal gradient gel electrophoresis (TGGE), single strand conformation polymorphism (SSCP) and concomitant sequence analysis of 16S Ribosomal ribonucleic acid ( $r R N A$ ) gene clones, have been used as a method for the rapid analysis of microbial diversity (Stralis-Pavese et al., 2006; Subramanyam and Das, 2009). An ideal method for analysis of diversity in complex microbial communities would enable the simultaneous measurement of composition, phylotype richness and community structure (Dunbar et al., 2000; Duran and Gonzailez, 2009). TRFLP analysis is one of the most frequently used high throughput fingerprinting methods, because it offers a compromise between the information gained and labor intensity (Schütte et al., 2008). TRFLP analysis has been applied for a wide range of soil samples, including agricultural soils, grassland, and forest soils and biological soil crusts (Hackl et al., 2004; Zhang et al., 2009; Nwuche and Ugoji, 2010). When coupled with analysis of clone libraries, additional specific information on the composition of microbial communities can also be obtained (Schütte et al., 2008). Phenanthrene is a PAH that has usually been detected in the reclaimed wastewater- or landfill leachate-contaminated soils (Han et al., 2009; He et al., 2010). Therefore, the aim of this study was to obtain an insight into the microbial community in the reclaimed wastewater- or landfill leachate-contaminated soils and to explore the microbial community change in response to phenanthrene amendment. The microbial communities were characterized by TRFLP in combination with $16 \mathrm{~S}$ rRNA gene clone library. Raw soils were collected in the year in the winter of 2009 in Changzhou, China, and the investigation was carried out between March and August in 2010 at College of Environmental Sciences and Engineering, Peking University, China.

\section{MATERIAL S AND METHODS}

Microcosm experiment set-up

Soils were collected from two different sites, including a soil from the grassland previously receiving four-year irrigation with reclaimed wastewater and another soil from the vicinity of an unmanaged composting site of municipal solid waste. Following sample collection, soils were air dried, homogenized, sieved through a $2-\mathrm{mm}$ screen and stored at $4{ }^{\circ} \mathrm{C}$ until use. Phenanthrene ( $98 \%$, Sinopharm Chemical Reagent Beijing Co., Ltd) dissolved in methanol was added to each empty microcosm chamber ( $150 \mathrm{~mL}$ serum bottle) with a total mass of $200 \mu \mathrm{g}$ phenanthrene per chamber. After the methanol evaporated, $2 \mathrm{~g}$ (dry weight) soil was added to each microcosm along with $10 \mathrm{~mL}$ phosphate buffered mineral media, as previously described (Mu and Scow, 1994). The bottles were sealed with rubber stoppers and aluminum seals to retain phenanthrene with the microcosms. The large $(150 \mathrm{~mL})$ air headspace in the bottles could provide oxic conditions for the duration of the experiments (LeBlanc et al., 2006). The sterile controls were obtained by autoclaving repeatedly (three times). Microcosms were incubated on a horizontal shaker $(\sim 100 \mathrm{rpm})$ at $25^{\circ} \mathrm{C}$. The microcosms were usually sacrificed at 5-d interval to measure the concentrations of phenanthrene in solid phase. All samples were prepared in two replicates.

\section{Phenanthrene extraction and analysis}

For the determination of phenanthrene in solid phase, the water-soil mixture in sacrificed microcosms was transferred to a $100-\mathrm{mL}$ centrifuge tube. After 10min centrifugation at $5,000 \mathrm{rpm}$, the supernatant was removed. The moist soil retained in tube was collected and then dried using a freeze drier (Alpha 1-2 LD plus, Martin Christ, German). 1 g dry soils were extracted three times with $10 \mathrm{~mL}$ acetone, using a $300 \mathrm{~W}$ ultrasonic processor (SB-5200 series, Ningpo Xingzhi Biotech. Co., China). The mixture was vigorously shaken then centrifuged at 5,000 rpm for $10 \mathrm{~min} .0 .2 \mathrm{~mL}$ of the supernatant was collected into a GC vial and diluted by 
$0.8 \mathrm{ml}$ methanol. The mixture was filtered with a $0.45-\mu \mathrm{m}$ syringe filter provided by Tianjin Jingteng Corp. (China). The filtrate was ready for HPLC analysis according to the method described by Huang et al. (2010) with minor modification. The analysis of phenanthrene concentration was conducted using a HPLC apparatus equipped with a LC-10AT pump, a UV-detector (Shimadzu), a Venusil PAH column (Agela Technologies) using methanol-water (90:10) as the mobile phase at a flow rate of $1 \mathrm{~mL} / \mathrm{min}$. Phenanthrene was detected by absorbance at $254 \mathrm{~nm}$. The injection volume was $10 \mu \mathrm{L}$ and retention times was $8.5 \mathrm{~min}$. The mean recovery rate was $93.7 \%$.

\section{TRFLP analysis}

DNA was extracted from duplicate microcosm samples using the UltraClean DNA extraction kit (Mobio Laboratories) following the manufacturer's instructions. Duplicate samples were not pooled, and the entire analysis for each was carried out separately. Bacterial 16S rRNA genes were amplified using universal eubacterial primers 27F-FAM (5'-GAGTTTGATCMTGGCTCAG-3', 5' endlabeled with carboxyfluorescine) and 1492R (5'GGTTACCTTGTTACGACTT-3') (Tiangen BioTech, China) using the following PCR program: $94^{\circ} \mathrm{C}(5 \mathrm{~min}) ; 94$ ${ }^{\circ} \mathrm{C}(30 \mathrm{~s}) ; 55^{\circ} \mathrm{C}(30 \mathrm{~s}) ; 72^{\circ} \mathrm{C}(1.5 \mathrm{~min})(30$ cycles $) ; 72{ }^{\circ} \mathrm{C}(5$ min)(Xie et al., 2010). PCR mixtures $(50 \mu \mathrm{L})$ included the HotMaster mixtures (Tiangen BioTech, China), primers (45 pmol each), and $4 \mu \mathrm{L}$ DNA sample. 300 ng PCR products were purified with QIA quick PCR purification kit (Qiagen Inc., German), following the manufacturer's instructions and digested with HaeIII (Saibaisheng Gene Tech, China) with a 6 hour incubation period. Additional digests (HhaI and $M s p I$ ) for TRFLP analyses were included to correlate the TRFLP fragment lengths to the in silico cut sites of the cloned 16S rRNA gene sequences and thus determine the identity of the significantly enriched fragments (Cupples and Sims, 2007; Xie et al., 2010). The fragment pattern was detected using an ABI 3730 DNA Analyzer (Applied Biosystems) set at the Genescan mode. Duplicate profiles from separate DNA extractions and separate PCR reactions for each sample were compared to identify the subset of reproducible fragment sizes. The average area of each reproducible peak of a sample was calculated and the set of reproducible peaks with newly calculated average areas was assigned as the average profile of the sample for use in all subsequent analyses. Terminal fragments under 100 fluorescent units or smaller than $50 \mathrm{bp}$ were excluded from the further analysis. Fragments that differed by less than 1 $\mathrm{bp}$ were clustered. The standardized binning criteria used to identify the subset of reproducible peaks were: (a) the peak had to appear in duplicate, (b) the relative area ratio had to be equal to or greater than $1 \%$ (Dunbar et al., 2001; Mills et al., 2003). Ribotype richness(S) equaled to the total number of distinct terminal fragment sizes in a profile. The Shannon diversity index $(\mathrm{H})$ and evenness (E) were calculated according to the standard methods (Mills et al., 2003; Falk et al., 2009). Bray-Curtis similarity index was calculated using PRIMER 5.0 software to evaluate the compositional similarity for microcosm samples (Clarke and Warwick, 2001).

\section{Cloning and sequencing}

The DNA templates used for construction of clone libraries were the same DNA preparations from which 16S rRNA genes for TRFLP analysis were amplified. The PCR conditions were the same as the abovementioned, except the forward primer was unlabeled (27F5'-AGAGTTTGATCMTGGCTCAG-3'). The PCR products were purified with QIA quick PCR purification kit (Qiagen Inc., German) and cloned into pMD19-T vector (Takara Corp, Japan) following the manufacturer's instruction. E. coli clones were grown on Luria-Bertani (LB) medium solidified with $15 \mathrm{~g} / \mathrm{L}$ agar with $50 \mu \mathrm{g} / \mathrm{L}$ ampicillin for $16 \mathrm{~h}$ at $37^{\circ} \mathrm{C}$. The white colonies were verified by PCR with primers M13 F (5'TGTAAAACGACGGCCAGT-3') and M13 R (5'AACAGCTATGACCATG-3'). Clones containing an insert of the correct size were sequenced at SinoGenoMax Co., Ltd. (Beijing). 58-72 clones recovered from each sample were successfully sequenced in this study. The partial 16S rRNA gene sequences determined in this study were deposited with GenBank under accession numbers HQ131964HQ132223. The Ribosomal Database Project (Center for Microbial Ecology, Michigan State University) analysis tool "classifier" was utilized to assign taxonomic identity (Wang et al., 2007).

\section{RESULTS AND DISCUSSION}

\section{Biodegradation}

In this study, the total amount of phenanthrene in supernatant was below $3 \%$ of that in the solid phase over the whole experiment. More than $90 \%$ of phenanthrene reduction in microcosms occurred, but decline was limited in the autoclaved controls (10.5$18 \%$ decrease), confirming a biological removal mechanism (Fig. 1). On day 5, a marked degradation was observed in each microcosm constructed either with composting site soil or grassland soil. Prior exposure to PAHs has been shown to reduce the length of the 
acclimation period associated with PAH degradation and increase the rate and extent of PAH degradation (Muckian etal., 2009).

\section{TRFLP analysis}

The microbial structure in PAH-contaminated site and its change have been usually depicted by DGGE analysis (Piskonen et al., 2005; Vinãs et al., 2005; Zhang et al., 2010) or phospholipid fatty acid (PLFA) analysis (Langworthy et al., 1998; Straube et al., 2003). However, TRFLP is a powerful tool used to monitor changes in the structure and composition of microbial communities (Liu et al., 1997; Marsh, 1999). TRFLP analysis has been applied for a wide range of soil samples, including agricultural soils, grassland and forest soils and biological soil crusts (Hackl et al., 2004). However, to the best of the authors' knowledge, this was the first report to use TRFLP to investigate the composition of bacterial community in leachate-contaminated soil or grassland soil irrigated reclaimed wastewater, also the response to $\mathrm{PAH}$ amendment. In this study, DNA samples for molecular analysis were extracted in duplicate from four microcosms including: (a) microcosm constructed with composting site soil on day $0\left(\right.$ microcosm $\left._{\mathrm{C} \text {-day } 0}\right)$, (b) microcosm constructed with composting site soil on day 30 $\left(\right.$ microcosm $\left._{\mathrm{C} \text {-day } 30}\right)$, (c) microcosm constructed with grassland soil on day 0 (microcosm $\left.m_{\text {G-day } 0}\right)$ and (d) microcosm constructed with grassland soil on day 30 $\left(\right.$ microcosm $\left._{\mathrm{G}-\mathrm{day} 30}\right)$. The number of different ribotypes (HaelII digest) for each microcosm sample was between 19 and 27 (Table 1, Fig. 2). In total, we detected 10 terminal restriction fragments (69 bp, 71 bp, 73 bp, 79bp, 80 bp, 82

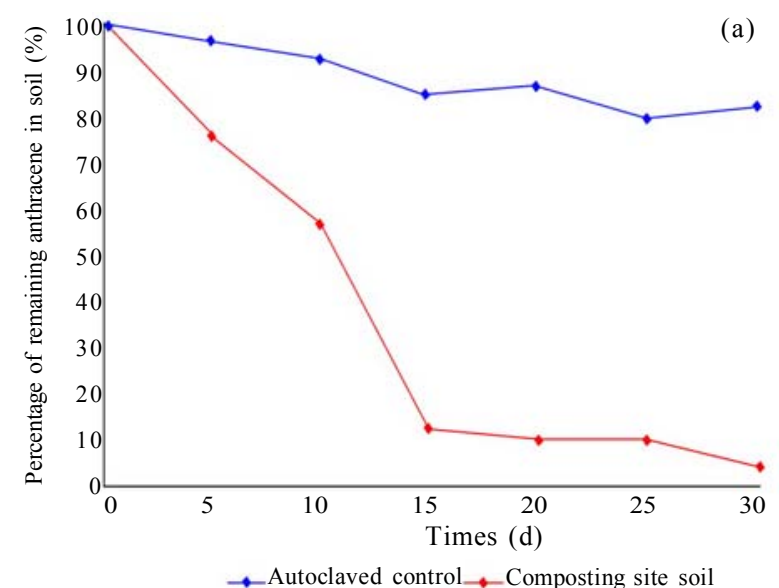

Fig. 1: Phenanthrene concentration with time in controls and in microcosms constructed with composting site soil (a), or grassland soil (b). The duplicate result illustrated the same trend bp, 83 bp, 114 bp, 115 bp and 123 bp) shared between microcosm $_{\mathrm{C} \text {-day } 0}$ and microcosm $\mathrm{G}_{\mathrm{G} \text {-day } 0}$. Compared with microcosm $_{\mathrm{C} \text {-day } 0}$, the ribotypes of $121 \mathrm{bp}, 131 \mathrm{bp}, 138$ bp, 164 bp, 196 bp, 203 bp, 215 bp, 219 bp, 260 bp, 265 bp, $319 \mathrm{bp}, 328 \mathrm{bp}$ and $329 \mathrm{bp}$ in microcosm ${ }_{\mathrm{C} \text {-day } 30}$ increased in relative abundance from below $1 \%$ (as they were not detectable on day 0 and $1 \%$ is the threshold resolution level). There were also increases in the relative abundance of fragments of $79 \mathrm{bp}, 80 \mathrm{bp}$ and $122 \mathrm{bp}$. Many other fragments decreased, with 12 fragments $(54 \mathrm{bp}, 71 \mathrm{bp}, 73$ bp, 83 bp, 113bp, 114bp,115bp, 124 bp, 157 bp, 158 bp, 159 bp and $259 \mathrm{bp}$ ) falling below the detectable $1 \%$ level. Compared with microcosm $\mathrm{G}_{\mathrm{G}-\mathrm{day} 0}, 10$ fragments $(113 \mathrm{bp}$, 122 bp, 147bp, 148 bp, 153 bp, 155 bp, 157 bp, 158 bp, 159 bp and $329 \mathrm{bp}$ ) in microcosm ${ }_{\mathrm{G} \text {-day } 30}$ increased in relative abundance from below $1 \%$. Fragment $69 \mathrm{bp}, 71 \mathrm{bp}, 72 \mathrm{bp}$, $79 \mathrm{bp}, 80 \mathrm{bp}, 82 \mathrm{bp}, 114 \mathrm{bp}, 115 \mathrm{bp}$ and $123 \mathrm{bp}$ also increased in the relative abundance. However, the relative abundance of 15 fragments (187 bp, 192 bp, $193 \mathrm{bp}, 195$ bp, 197 bp, 202 bp, 217 bp, 230 bp, 232 bp, 260 bp, 262 bp, $264 \mathrm{bp}, 324 \mathrm{bp}, 328 \mathrm{bp}$ and $330 \mathrm{bp}$ ) fell below $1 \%$. Other 3 fragments ( $73 \mathrm{bp}, 83 \mathrm{bp}$ and $215 \mathrm{bp}$ ) also decreased in the relative abundance. After a 30-day experimental period, for microcosm constructed with composting site soil, ribotype richness gained a very slight increase, but Shannon-Weiner diversity index and evenness decreased (Table 1). For microcosm constructed with grassland soil, each of Shannon-Weiner diversity index, evenness, ribotype richness decreased. Bray-Curtis similarity index showed microcosm $\mathrm{G}_{\mathrm{G} \text { day } 0}$ and microcosm $\mathrm{G}_{\mathrm{G} \text {-day30 }}$ only had $52.2 \%$ similarity (Table 2 ). However, the similarity between microcosm $\mathrm{C}_{\mathrm{C} \text {-dy } 0}$ and microcosm $\mathrm{C}_{\mathrm{C} \text {-day30 }}$

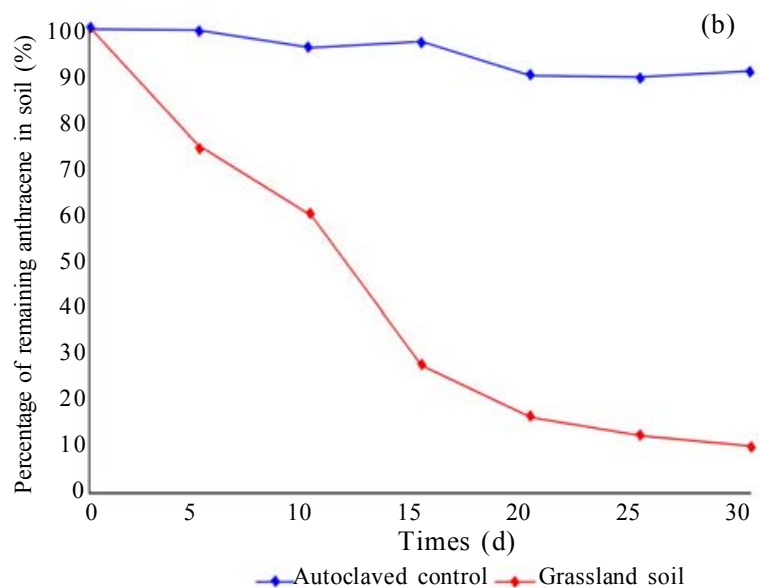


Int. J. Environ. Sci. Tech., 8 (2), 321-330, Spring 2011

Table 1: Comparison of diversity and evenness indices for the TRFLP profiles (HaeIII digest) from the four microcosm samples

\begin{tabular}{lccc}
\hline Samples & Ribotype $(\mathrm{S})$ & Diversity $(\mathrm{H})$ & Evenness $(\mathrm{E})$ \\
\hline Microcosm & 19 & 2.70 & 0.92 \\
Microcos0 & 20 & 2.52 & 0.84 \\
Microcosm & 27 & 3.11 & 0.94 \\
Microcos30 & 27 & 2.71 & 0.91 \\
\hline
\end{tabular}

$\mathrm{S}=$ total number of bands/profile (richness). $\mathrm{H}=$ Shannon diversity index, $\mathrm{H}=-\Sigma\left(\mathrm{p}_{\mathrm{i}}\right)\left(\log 2 \mathrm{p}_{\mathrm{i}}\right)$, where $\mathrm{p}_{\mathrm{i}}$ is the individual peak area. $\mathrm{H}_{\max }=\log 2(\mathrm{~S}) . \mathrm{E}=\mathrm{H} / \mathrm{H}_{\max }$.

Table 2: Bray-Curtis similarity index for the TRFLP profiles (HaeIII digest) from the four microcosm samples

\begin{tabular}{|c|c|c|c|c|}
\hline Samples & Microcosm $_{\text {C-day } 0}$ & Microcosm $_{\text {C-day } 30}$ & Microcosm $_{\mathrm{G}-\text { day } 0}$ & Microcosm $_{\mathrm{G}-\text { day } 30}$ \\
\hline Microcosm $_{\text {C-day0 }}$ & 100 & & & \\
\hline Microcosm $_{\text {C-day } 30}$ & 34.9 & 100 & & \\
\hline Microcosm $\mathrm{G}_{\mathrm{G} \text {-day } 0}$ & 50.4 & 35.7 & 100 & \\
\hline Microcosm $_{\mathrm{G}-\text { day } 30}$ & 76.9 & 43.5 & 52.2 & 100 \\
\hline
\end{tabular}

was even lower (34.9\%). Altogether, the abovementioned indices revealed big differences of microbial community structure over the experimental period. Biostimulation can usually induce a remarkable shift in the composition of the bacterial community due to both the biodegradation process and the addition of carbons or nutrients (Vinãs et al., 2005; Gennaro et al., 2009). Moreover, changes in hydrocarbon content in soils also results in bacterial community structure (Wiinsche et al., 1995). Langworthy et al. (1998) and Yousefi Kebria et al. (2009) have revealed the genotypic and phenotypic change of riverine microbial community with increased PAH concentration. Muckian et al. (2009) have also revealed the significant change of the microbial community in soil in response to fluoranthene or phenanthrene amendment. Moreover, a field survey in a creosote-polluted soil has indicated that gramnegative bacteria were positively correlated with PAH concentration while fungi and gram-negative bacteria were not favored by increased PAH concentrations (Törneman et al., 2008), which suggested a selection of microbial community towards to a higher PAH concentration. Piskonen et al. (2005) have proven that significant selection occurred in the microbial community as a result of naphthalene biodegradation. Enrichment of PAH-degraders seems to be a common phenomenon during the course of PAH biodegradation (Whyte et al., 1999; Piskonen et al., 2005). In this study, compared with microcosm ${ }_{\text {C-day }}$, $79 \mathrm{bp}, 80 \mathrm{bp}, 121 \mathrm{bp}$ and $219 \mathrm{bp}$ (HaeIII digest) in microcosm $_{\mathrm{C} \text {-day30 }}$ were significantly enriched $(5 \%$ or more increase in the relative abundance) (Fig.1). The enrichment of these fragments during phenanthrene biodegradation might be attributed to the enrichment of some PAH-degraders.

\section{Phylogeny}

The phylogenetic description of the change of dominant bacterial groups is also important for better understanding of microbial community. In this study, many known phyla (Bacteroidetes, Proteobacteria, Actinobacteria, Acidobacteria, Planctomycetes, Nitrospira, Gemmatimonadetes, Firmicutes, Chloroflexi, TM7 and Verrucomicrobia), together with unclassified bacteria were detected, although only Bacteroidetes, $\alpha-, \beta-, \gamma-, \delta$-proteobacteria, Acidobacteria, Gemmatimonadetes and unclassified bacteria were shared among all microcosm samples (Fig.3). For microcosm $\mathrm{C}_{\text {-day0 }}$, the 72 clones recovered from soil DNA sample were distributed as follows: $\alpha$ proteobacteria $20.8 \%$, Actinobacteria $19.4 \%$, Unclassified bacteria $13.9 \%$ and Acidobacteria $12.5 \%$ and other minor phyla groups (each below 10\%) including Bacteroidetes, $\beta$-, $\gamma$-, $\delta$-proteobacteria, Planctomycetes, Nitrospira, Gemmatimonadetes, Chloroflexi, TM7 and Verrucomicrobia. However, the major phylum types (no less than $10 \%$ ) of 65 clones recovered from the microcosm $\mathrm{C}_{\mathrm{C} \text {-da30 }}$ DNA sample were only $\beta$-proteobacteria (51.0\%) and Acidobacteria $(12.0 \%)$. Actinobacteria and $\alpha$-proteobacteria decreased greatly in the relative abundance (more than $10 \%$ ). Many other phyla such as Acidobacteria, Planctomycetes, Chloroflexi, TM7 and Verrucomicrobia were not detected in microcosm $\mathrm{C}_{\text {-day30 }}$ soil sample. A large shift in $\alpha$-, $\beta$-proteobacteria and Actinobacteria occurred over the 30-day experiment. For microcosm $\mathrm{G}_{\text {-day } 0}$, the major phylum types of 58 clones were $\alpha$-proteobacteria (25.9\%), Acidobacteria (13.8\%), $\beta$-proteobacteria $(12.1$ $\%$ ) and Actinobacteria (12.1\%), indicating a different phylum composition compared with microcosm $\mathrm{C}_{\mathrm{C} \text {-day } 0}$. However, the main phylum types of 65 clones recovered 
from the microcosm $\mathrm{G}_{\mathrm{G}-\mathrm{day} 30}$ DNA sample were $\beta$ proteobacteria $(29.2 \%)$, $\alpha$-proteobacteria $(15.4 \%)$ Acidobacteria (13.9\%), $\delta$-proteobacteria (12.9\%) and $\gamma$-proteobacteria $(10.8 \%)$. A large shift in Bacteroidetes, $\alpha-, \beta-, \gamma-, \delta$-proteobacteria was observed. Several previous reports have also depicted the phylogenetic information of microbial community in PAHcontaminated site. A recent work has shown the dominance of $\alpha$-, $\beta$ - and $\gamma$-proteobacteria in the soil/ water system for PAH biodegradation (Chang et al., 2007). A more recent work has also shown the dominance of $\beta$-proteobacteria and $\gamma$-proteobacteria in aged PAH-contaminated soil (Cébron et al., 2009). These works usually show the dominance of proteobacteria, especially $\beta$-proteobacteria. However, the dominant bacterial phylum in PAHcontaminated sites is not always proteobacteria. For examples, the dominance of Firmicutes, together with $\beta$-proteobacteria, has been detected in e-waste processing sites with heavy PAH pollution (Zhang et al., 2010). Vinãs et al. (2005) have revealed remarkable shift in the phylum composition of the bacterial community in response to PAH degradation during bioremediation of heavily creosote-contaminated soil. They found that there was a shift in dominant group from $\alpha$-proteobacteria to $\gamma$-proteobacteria, $\alpha$ Proteobacteria and Bacteroidetes in the nonnutrient treatment and to $\gamma$-proteobacteria, $\beta$-proteobacteria, $\alpha$-Proteobacteria in the nutrient treatment, respectively. However, in this study, the shift of dominant phyla during PAH biodegradation was different from their result. For the microcosm $\mathrm{C}_{\mathrm{C} \text { day } 0}$, the major phyla were $\alpha$ proteobacteria $20.8 \%$, Actinobacteria $19.4 \%$, but the bacterial groups in microcosm $\mathrm{C}_{\mathrm{C} \text {-day } 30}$ were mainly represented by $\beta$-proteobacteria $(51.0 \%)$ and Acidobacteria (12.0\%). Also, for the microcosm constructed with grassland soil, a large shift in Bacteroidetes, $\alpha-, \beta-, \gamma-, \delta$-proteobacteria was observed over the experiment. Moreover, Fig. 3 showed a different phylum shift pattern in two microcosms constructed with
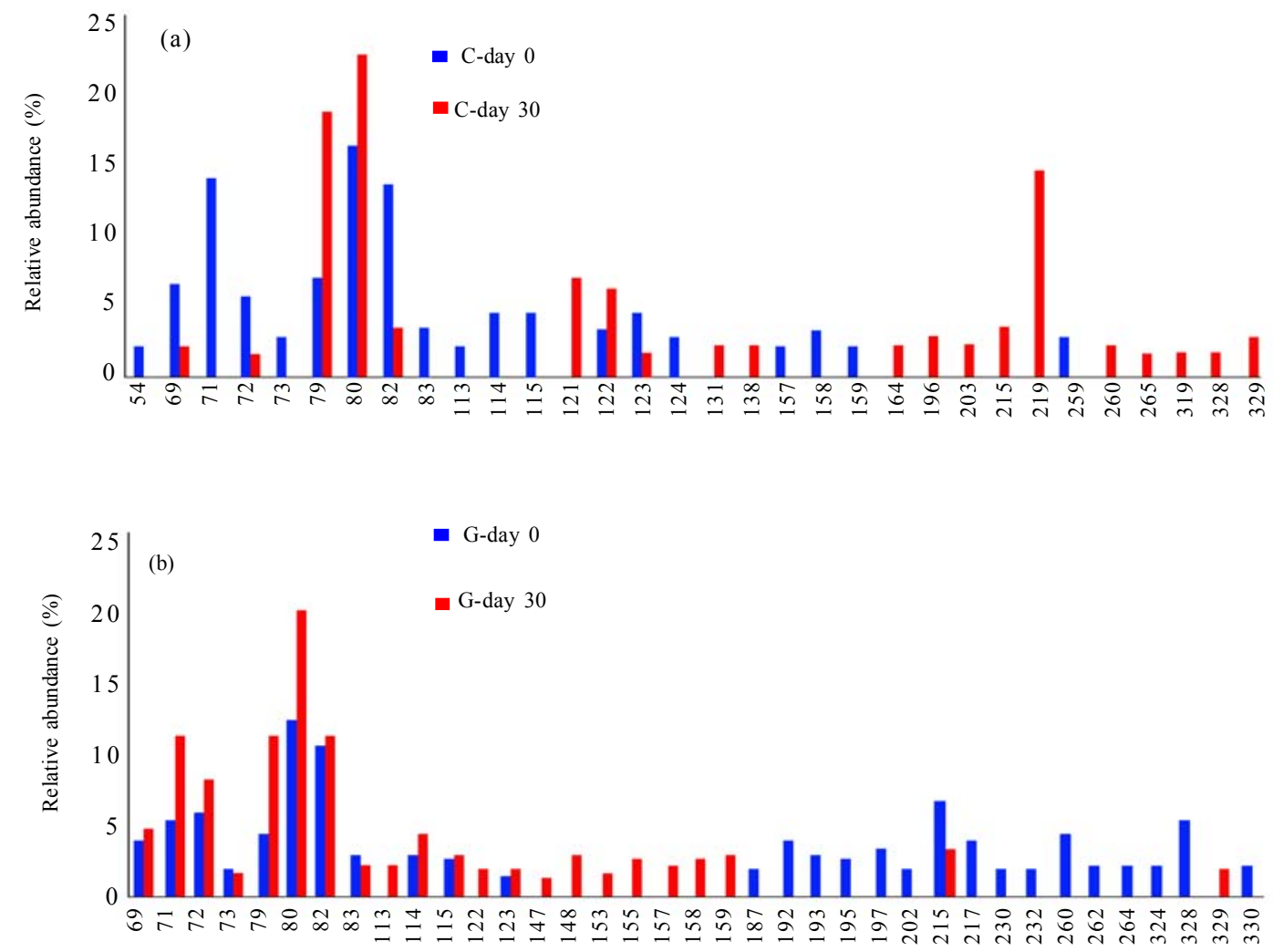

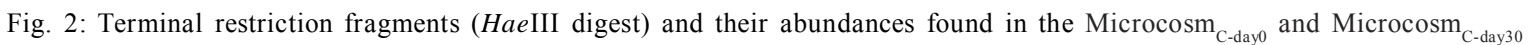

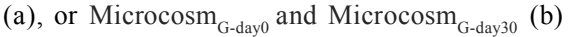


different soils. There are complex interactions between bacterial species and medium conditions that influence the biodegradation capacity of the microbial communities involved in bioremediation processes (Vinãs et al., 2005).
In agreement with TRFLP analysis, the impact of phenanthrene amendment on microbial community was dependent on the soil source used for microcosm construction. Many others' studies have shown the
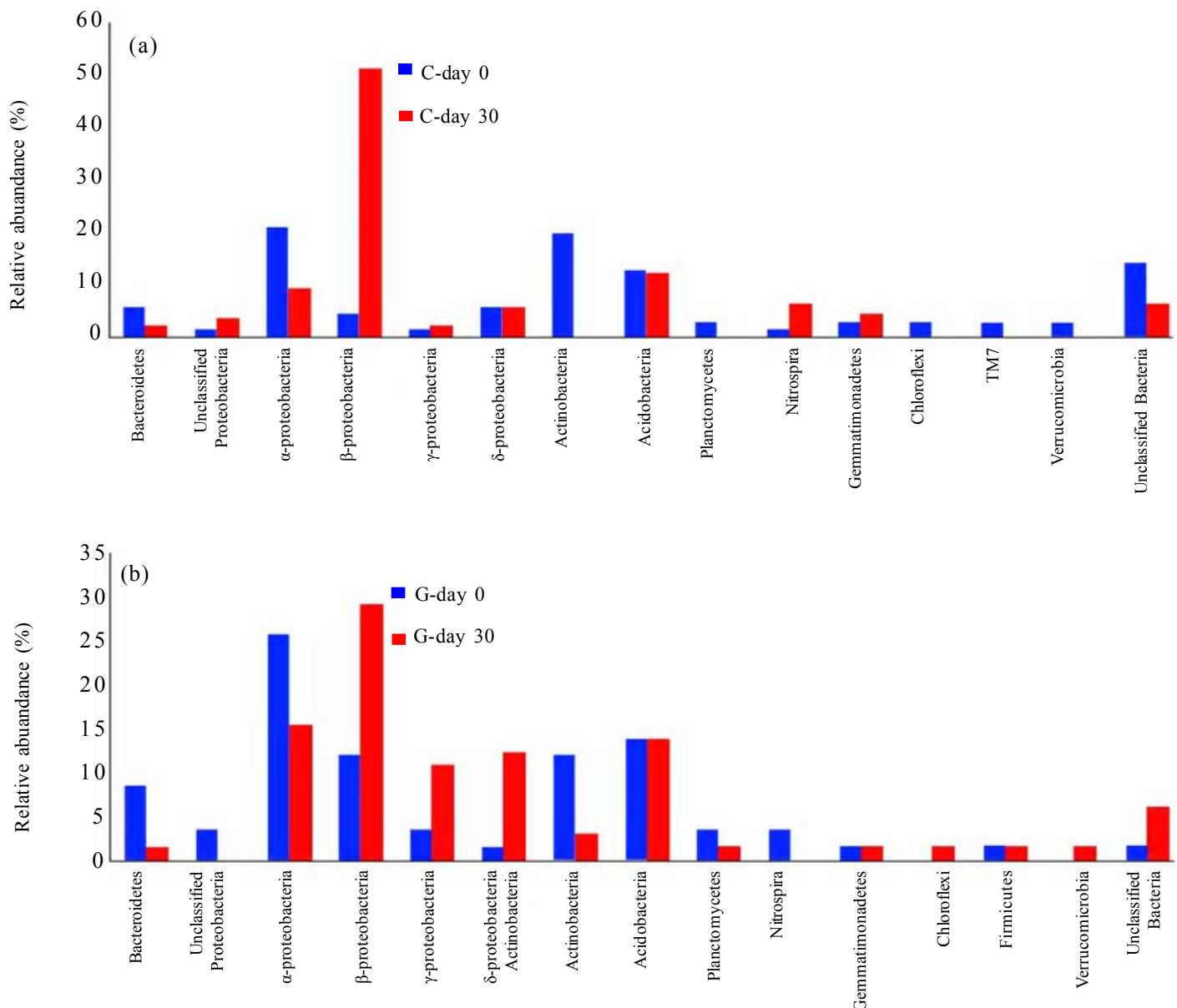

Fig. 3: Comparison of the quantitative contribution of the clones affiliated with different phyla and sub-phyla to the total number of clones from the microcosm samples with composting site soil (a), or grassland soil (b). Clones not classified to any known phylum are included as unclassified bacteria

Table 3: Comparison of significantly enriched TRFLP fragments to clone restriction enzyme cut sites predicted from sequence analyses to confirm the identity

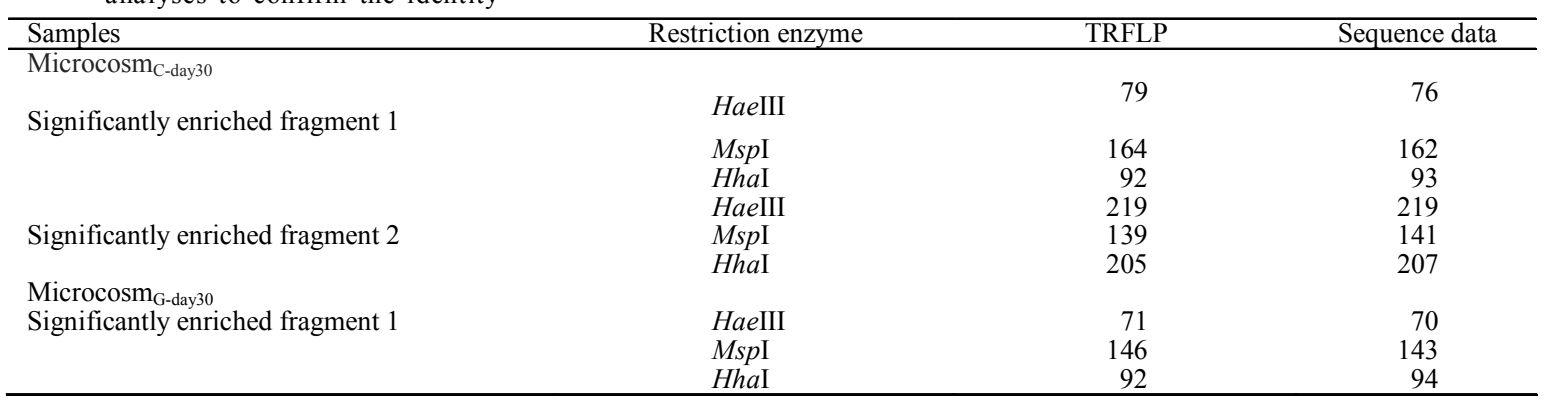


Table 4: Phylogenetic affiliation of each dominant enriched fragment (HaeIII digest) as determined with the RDP analysis tool "classifier"

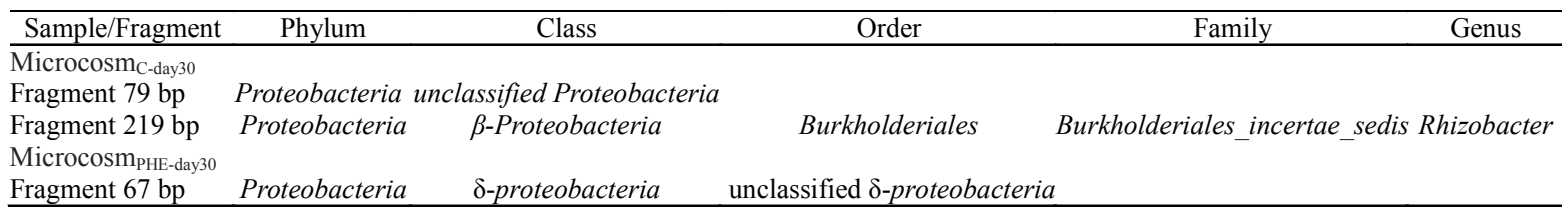

impact of contamination on bacterial communities is dependent on soil sources (MacNaughton et al., 1999; Andreoni et al., 2004; Muckian et al., 2009).

\section{Identity of significantly enriched TRFLP fragments}

Since the enrichment of these fragments occurred with the significant biodegradation of phenanthrene, the enrichment of these fragments may have some links to the biodegradation. Therefore, the identities of significantly enriched TRFLP fragments were also investigated. Two additional restriction enzymes (MSPI and $H h a \mathrm{I})$ were used to provide a positive identification of the HaeIII TRFLP enriched fragments. The abundant fragments obtained from all TRFLP restriction enzymes were compared to those obtained from in silico digests to determine the 16S rRNA sequence of each enriched fragment (Xie et al., 2010). A comparison of TRFLP cut sites and in silico cut sites was presented (Table 3). The slight differences (2-3 bases) between the measured fragment lengths and those predicted using sequence data have also been noted elsewhere (Liu et al., 1997; Clement et al., 1998; Luo et al., 2009). The taxonomic identity, as determined by the RDP analysis tool "classifier" (Wang et al., 2007), of each enriched fragment (cloned 16S rRNA sequence), thus was presented (Table 4). $219 \mathrm{bp}$ (HaeIII digest) gained from microcosm $\mathrm{C}_{\mathrm{C} \text {-day } 30}$ was identified as the genus of Rhizobacter. $79 \mathrm{bp}$ gained from microcosm $\mathrm{m}_{\mathrm{C}-\mathrm{day} 30}$ belonged to unclassified Proteobacteria. $67 \mathrm{bp}$ (HaeIII digest) gained from microcosm $_{\mathrm{G} \text {-day30 }}$ fell into unclassified $\delta$-proteobacteria. However, unfortunately, the taxonomic identity of $80 \mathrm{bp}$, $121 \mathrm{bp}$ from microcosm $\mathrm{C}_{\mathrm{C} \text {-day } 30}$, and $79 \mathrm{bp}$ and $80 \mathrm{bp}$ from microcosm $_{\mathrm{G} \text {-day } 30}$ remained unknown, possibly due to the limited volume of clone library. The bioremediation is a strategy for PAHs removal because some microorganisms can metabolize PAHs to inert substances, $\mathrm{CO}_{2}$ and water (Santos et al., 2008). According to a summary by Wong et al. (2002), various classes of bacteria previously isolated from PAHs-contaminated sites belong to Pseudomonas, Alcaligenes, Vibrio, Mycobacterium, Comamonas, Arthrobacter, Burkholderia,
Flavobacterium, Micrococcus, Pasteurella and Sphingomonas. In this study, the significantly enriched fragments (219 bp) (HaeIII digest) gained from microcosm $_{\mathrm{C} \text {-day30 }}$ was identified as Rhizobacter, while 79 bp gained from microcosm $\mathrm{C}_{\mathrm{C} \text {-day30 }}$ and $67 \mathrm{bp}$ from microcosm $_{\mathrm{G} \text {-day } 30}$ could be only classified into the phylum of proteobacteria and sub phylum of $\delta$-proteobacteria respectively. Some Rhizobacteria are considered as potential biocontrol and plant growth-promoting agents (Nautiyal et al., 2008). However, surprisingly, no isolate belonging to Rhizobacter has previously been founded in PAH-contaminated soils and had links to PAH biodegradation. Therefore, the roles of these ribotypes enriched with PAH biodegradation process still remained unclear.

\section{CONCLUSION}

TRFLP coupled with $16 \mathrm{~S}$ rRNA clone library could effectively monitor the shift of microbial community in the PAH-contaminated soils in response to phenanthrene amendment. A big shift in community structure and significant enrichment of several ribotypes occurred with the 30-day phenanthrene biodegradation. The shift of dominant phyla during PAH biodegradation was different from others' previous results. Also, the impact of phenanthrene amendment on microbial community was dependent on the soil source. However, the roles of these ribotypes enriched with $\mathrm{PAH}$ biodegradation process still remained unclear. Therefore, further study is still necessary to explore the biodegradation mechanism of phenanthrene in the PAHcontaminated soils.

\section{ACKNOWLEDGEMENTS}

This work was financially supported by National Natural Science Foundation of China (No. 50979002).

\section{REFERENCES}

Abdulsalam, S.; Bugaje, I. M.; Adefila, S. S.; Ibrahim S., (2011). Comparison of biostimulation and bioaugmentation for remediation of soil contaminated with spent motor oil. Int. J. Environ. Sci. Tech., 8 (1), 187-194 (8 pages). 
Andreoni, V.; Cavalca, L.; Rao, M. A.; Nocerino, G.; Bernasconi, S.; Dell'Amico, E.; Colombo, M.; Gianfreda, L., (2004). Bacterial communities and enzyme activities of PAHs polluted soils. Chemosphere, 57 (5), 401-412 (12 pages).

Arulazhagan, P.; Vasudevan, N.; Yeom, I. T., (2010). Biodegradation of polycyclic aromatic hydrocarbon by a halotolerant bacterial consortium isolated from marine environment. Int. J. Environ. Sci. Tech., 7 (4), 639-652 (14 pages).

Cébron, A.; Beguiristain, T.; Faure, P.; Norini, M. P.; Masfaraud, J. F.; Leyval, C., (2009). Influence of vegetation on the in situ bacterial community and polycyclic aromatic hydrocarbon (PAH) degraders in aged PAH-contaminated or thermaldesorption-treated soil. Appl. Environ. Microbiol., 75 (19), 63226330 (9 pages)

Chang, Y. T.; Lee, J. F.; Chao, H. P., (2007). Variability of communities and physiological characteristics between free-living bacteria and attached bacteria during the PAH biodegradation in a soil/water system. Eur. J. Soil Biol., 45 (3), 283-296 (14 pages).

Chen, Y.; Wang, C. X.; Wang, Z. J., (2005). Residues and source identification of persistent organic pollutants in farmland soils irrigated by effluents from biological treatment plants. Environ. Int., 31 (6), 778-783 (6 pages).

Clarke, K. R.; Warwick, R. M., (2001). Change in marine communities: an approach to statistical analysis and interpretation, $2^{\text {nd }}$ ed. PRIMER-E, Plymouth Marine Laboratory, Plymouth, UK, 172 pp.

Clement, B. G.; Kehl, L. E.; DeBord, K. L.; Kitts, C. L., (1998). Terminal restriction fragment patterns (TRFPs), a rapid, PCRbased method for the comparison of complex bacterial communities. J. Microbiol. Methods, 31 (3), 135-142 (8 pages).

Cunliffe, M.; Kertesz, M. A., (2006). Effect of Sphingobium yanoikuyae B1 inoculation on bacterial community dynamics and polycyclic aromatic hydrocarbon degradation in aged and freshly PAH-contaminated soils. Environ. Pollut., 144 (1), 228237 (10 pages).

Cupples, A. M.; Sims, G. K., (2007). Identification of in situ 2,4dichlorophenoxyacetic acid-degrading soil microorganisms using DNA-stable isotope probing. Soil Biol. Biochem., 39 (1), 232238 (7 pages).

Dunbar, J.; Ticknor, L. O.; Kuske, C. R., (2000). Assessment of microbial diversity in four southwestern United States soils by 16S rRNA gene terminal restriction fragment analysis. Appl. Environ. Microbiol., 66 (7), 2943-2950 (18 pages).

Dunbar, J. M.; Ticknor, L. O.; Kuske, C. R., (2001). Phylogenetic specificity and reproducibility and new method for analysis of terminal restriction fragment profiles of $16 \mathrm{~S}$ rRNA genes from bacterial communities. Appl. Environ. Microbiol., 67 (1), 190197 (8 pages).

Duran, A. C.; Gonzailez, A., (2009). Determination of lead, naphthalene, phenanthrene, anthracene and pyrene in street dust. Int. J. Environ. Sci. Tech., 6 (4), 663-670 (8 pages)

Falk, M. W.; Song, K. G.;Matiasek, M. G.; Wuertz, S., (2009). Microbial community dynamics in replicate membrane bioreactors- natural reproducible fluctuations. Water. Res., 43 (3), 842-852 (11 pages).

Gennaro, P. D.; Morenoa, B.; Annonib, E.; García-Rodríguez, S.; Bestetti, G.; Beniteza, E., (2009). Dynamic changes in bacterial community structure and in naphthalene dioxygenase expression in vermicompost-amended PAH-contaminated soils. J. Hazard. Mater., 172 (2-3), 1464-1469 (6 pages)

Grant, R. J.; Muckian, L. M.; Clipson, N. J. W.;Doyle, E. M., (2007). Microbial community changes during the bioremediation of creosote-contaminated soil. Lett. Appl. Microbiol., 44 (3),
293-300 (8 pages).

Hackl, E.; Zechmeister-Boltenstern, S.; Bodrossy, L.; Sessitsch, A., (2004). Comparison of diversities and compositions of bacterial populations inhabiting natural forest soils. Appl. Environ. Microbiol., 70 (9), 5057-5065 (9 pages).

Han, X. J.; Li, L. Q.;Pan, G. X.; Hu, Z. L., (2009). Pollution characteristics of polycyclic aromatic hydrocarbons in soils from farmland around the domestic refuse dump. Eco. Environ. Sci., 18 (4), 1251-1255 (5 pages).

Haritash, A. K.; Kaushik, C. P., (2009). Biodegradation aspects of polycyclic aromatic hydrocarbons (PAHs): A Rev. J. Hazard. Mater., 169 (1-3), 1-15 (15 pages).

He, J. J., (2008). Study on PAHs degraders and microbial diversity analysis in petroleum-contaminated soil. M.Sc. thesis, Xinjiang Agricultural University.

He, J. T.; Jin, A. F.; Chen, S. N.; Wei, Y. X., (2010). Distribution characteristics of soil PAHs in reclaimed water irrigation area in the southeastern suburb of Beijing. J. Agro-Environ. Sci., 29 (4), 666-673 (8 pages).

Huang, Y.; Zhang, S. Y.; Lv, M. J.; Xie, S. G., (2010). Biosorption characteristics of ectomycorrhizal fungal mycelium to anthracene. Biomed. Environ. Sci., 23 (5), 167-172 (6 pages).

Langworthy, D. E.; Stapleton, R. D.; Sayler, G. S.; Findlay, R. H., (1998). Genotypic and phenotypic responses of a riverine microbial community to polycyclic aromatic hydrocarbon contamination. Appl. Environ. Microbiol., 64 (9), 3422-3428 (7 pages).

LeBlanc, L. A.; Gulnick, J. D.; Brownawell, B. J.; Taylor, G. T., (2006). The influence of sediment resuspension on the degradation of phenanthrene in flow-through microcosms. Mar. Environ. Res., 61 (2), 202-223 (22 pages).

Liu, W. T.; Marsh, T. L.; Cheng, H.; Forney, L. J., (1997). Characterization of microbial diversity by determining terminal restriction fragment length polymorphisms of genes encoding 16S rRNA. Appl. Environ. Microbiol., 63 (11), 4516-4522 (7 pages).

Luo, C.; Xie, S. G.; Sun, W.; Li, X.; Cupples, A. M., (2009). Identification of a novel toluene-degrading bacterium from the candidate phylum TM7, as determined by DNA stable isotope probing. Appl. Environ. Microbiol., 75 (13), 4644-4647 (4 pages).

MacNaughton, S. J.; Stephen, J. R.; Venosa, A. D.; Davis, G. A.; Chang, Y. J.; White, D. C., (1999). Microbial population changes during bioremediation of an experimental oil spill. Appl. Environ. Microbiol., 65 (8), 3566-3574 (9 pages).

Marsh, T. L., (1999). Terminal restriction fragment length polymorphism (T-RFLP): An emerging method for characterizing diversity among homologous populations of amplification products. Curr. Opin. Microbiol., 2 (3), 323-327 (5 pages).

Mills, D. K.; Fitzgeralda, K.; Litchfielda, C. D.; Gillevetb, P. M., (2003). A comparison of DNA profiling techniques for monitoring nutrient impact on microbial community composition during bioremediation of petroleumcontaminated soils. J. Microbiol. Methods., 54 (1), 57-74 (18 pages).

Mu, D. Y.; Scow, K. M., (1994). Effect of trichloroethylene (TCE) and toluene concentrations on TCE and toluene biodegradation and the population density of TCE and toluene degraders in soil. Appl. Environ. Microbiol., 60 (7), 2661-2665 (5 pages).

Muckian, L. M.; Grant, R. J.; Clipson, N. J. W.; Doyle, E. M.,(2009). Bacterial community dynamics during bioremediation of phenanthrene- and fluoranthene- 
amended soil. Int. Biodeterior. Biodegrad., 63 (1), 52-56 (5 pages).

Nautiyal, C. S.; Govindarajan, R.; Lavania, M.; Pushpangadan, P., (2008). Novel mechanism of modulating natural antioxidants in functional foods: Involvement of plant growth promoting rhizobacteria NRRL B-30488. J. Agric. Food. Chem., 56 (12), 4474-4481 (8 pages).

Nwuche, C. O.; Ugoji, E. O., (2010). Effect of co-existing plant specie on soil microbial activity under heavy metal stress. Int. J. Environ. Sci. Tech., 7 (4), 697-704 (8 pages).

Piskonen, R.; NyyssÖnen, M.; Rajamäki, T.; Itävaara, M., (2005). Monitoring of accelerated naphthalene-biodegradation in a bioaugmented soil slurry. Biodegradation, 16 (2), 127-134 (8 pages).

Santos, E. C.; Jacques, R. J. S.; Bento, F. M.; do Carmo, R.; Peralba, M.; Selbach, P. A.; Flá, S.; Camargo, F. A. O., (2008). Anthracene biodegradation and surface activity by an iron-stimulated Pseudomonas sp. Bioresour. Tech., 99 (7), 2644-2649 (6 pages).

Schütte, U. M. E.; Abdo, Z.; Bent, S. J.; Shyu, C.; Williams, C. J.; Pierson, J. D.; Forney, L. J., (2008). Advances in the use of terminal restriction fragment length polymorphism (T-RFLP) analysis of $16 \mathrm{~S}$ rRNA genes to characterize microbial communities. Appl. Microbiol. Biotech., 80 (3), 365-380 (16 pages).

Stralis-Pavese, N.; Bodrossy, L.; Reichenauer, T. G.; Weilharter, A.; Sessitsch, A., (2006). 16S rRNA based T-RFLP analysis of methane oxidizing bacteria-Assessment, critical evaluation of methodology performance and application for landfill site cover soils. Appl. Soil. Ecol., 31 (3), 251-266 (16 pages).

Straube, W. L.; Nestler, C. C.; Hansen, L. D.; Ringleberg, D.; Pritchard, P. H.; Jones-Meehan, J., (2003). Remediation of polyaromatic hydrocarbons (PAHs) through landfarming with biostimulation and bioaugmentation. Acta. Biotech., 23 (2-3), 179-196 (18 pages).

Subramanyam, B. M. E.; Das, A., (2009). Linearized and nonlinearized isotherm models comparative study on adsorption of aqueous phenol solution in soil. Int. J. Environ. Sci. Tech., 6 (4), 633-640 (8 pages)

Tao, S.; Cui, Y. H.; Xu, F. L.; Li, B. G.; Cao, J.; Liu, W. X.; Schmitt, G.; Wang, X. J.; Shen, W. R.; Qing, B. P.; Sun, R., (2004). Polycyclic aromatic hydrocarbons (PAHs) in agricultural soil and vegetables from Tianjin. Sci. Total. Environ., 320 (1), 1124 (14 pages).

Törneman, N.; Yang, X. H.; Bååth, E.; Bengtsson, G., (2008). Spatial covariation of microbial community composition and polycyclic aromatic hydrocarbon concentration in a creosotepolluted soil. Environ. Toxicol. Chem., 27 (5), 1039-1046 (8 pages).

Vinãs, M.; Sabaté, J.; Espuny, M. J.; Solanas, A. M., (2005). Bacterial community dynamics and polycyclic aromatic hydrocarbon degradation during bioremediation of heavily creosotecontaminated soil. Appl. Environ. Microbiol., 71 (11), 7008 7018 (11 pages).

Wang, Q.; Garrity, G. M.; Tiedje, J. M.; Cole, J. R., (2007). Naïve Bayesian classifier for rapid assignment of rRNA sequences into the new bacterial taxonomy. Appl. Environ. Microbiol., 73 (16), 5261-5267 (7 pages).

Whyte, L. G.; Bourbonniere, L.; Bellerose, C.; Greer, C. W., (1999). Bioremediation assessment of hydrocarbon-contaminated soils from the high arctic. Bioremed. J., 3 (1), 69-79 (11 pages).

Wiinsche, L.; Briiggemann, L.; Babel, W., (1995). Determination of substrate utilization patterns of soil microbial communities: An approach to assess population changes after hydrocarbon pollution. FEMS Microbiol. Ecol., 17 (4), 295-306 (12 pages).

Wong, J. W. C.; Lai, K. M.; Wan, C. K.; Ma, K. K.; Fang, M., (2002). Isolation and optimization of PAH-degradative bacteria from contaminated soil for PAHs bioremediation. Water Air Soil Pollut., 139 (1-4), 1-13 (13 pages).

Xie, S. G.; Sun, W. M.; Luo, C. L.; Cupples, A. M., (2010). Stable isotope probing identifies novel $m$-xylene degraders in soil microcosms from contaminated and uncontaminated sites. Water, Air, Soil Pollut., 212 (1-4), 113-122 (10 pages).

Yousefi Kebria, D.; Khodadadi, A.; Ganjidoust, H.; Badkoubi, A.; Amoozegar, M. A., (2009). Isolation and characterization of a novel native Bacillus strain capable of degrading diesel fuel. Int. J. Environ. Sci. Tech., 6 (3), 435-442 (8 pages).

Yuan, S. Y.; Wei, S. H.; Chang, B. V., (2000). Biodegradation of polycyclic aromatic hydrocarbons by a mixed culture. Chemosphere, 41 (9), 1463-1468 (6 pages).

Zhang, H.; Dang, Z.; Zheng, L. C.; Yi, X. Y., (2009). Remediation of soil co-contaminated with pyrene and cadmium by growing maize (Zea mays L.) Int. J. Environ. Sci. Tech., 6 (2), 249-258 (10 pages).

Zhang, W.; Wang, H.; Zhang, R.; Yu, X. Z.; Qian, P. Y.; Wong, M. H., (2010). Bacterial communities in PAH contaminated soils at an electronic-waste processing center in China. Ecotoxicology, 19 (1), 96-104 (9 pages).

Zhang, Y. L., (2008). Ecologieal effects of the utilization of sewage and sewage sludge on microbes in soil. Ph.D. thesis, Shandong University.

\section{AUTHOR (S) BIOSKETCHES}

Zhang, S. Y., M.Sc. candidate for Environmental Science, College of Environmental Sciences and Engineering, Peking University, Beijing, China. Email: zhangshuying2010@gmail.com

Wang, Q. F., M.Sc. candidate for Environmental Science, College of Environmental Sciences and Engineering, Peking University, Beijing, China. Email:08wqf@163.com

Xie, S. G., Ph.D., Associate Professor, College of Environmental Sciences and Engineering, Peking University, Beijing, China. Email:xiesg@pku.edu.cn

How to cite this article: (Harvard style)

Zhang, S. Y.; Wang, Q.F.; Xie, S. G.; (2011). Microbial community changes in contaminated soils in response to phenanthrene amendment. Int. J. Environ. Sci. Tech., 8 (2), 321-330. 